\title{
Letter to the Editor: Is Adult Male Circumcision a Viable Public Health Strategy for HIV Prevention Outside Sub-Saharan Africa?
}

\author{
Dorota Rogowska-Szadkowska, M.D., Ph.D.
}

\section{Dear Editor:}

In their article "Making the Case for Circumcision as a Public Health Strategy: Opening the Dialogue" Castro et al. ${ }^{1}$ propose opening up a dialogue on adult male circumcision (AMC) in the United States, but it would be advisable to tackle some of the issues which are relevant not only in the U.S. context.

Large-scale studies conducted in Africa have shown that $\mathrm{AMC}$ reduces the risk to men of infection through heterosexual intercourse by approximately $51-60 \%$, but it was also stressed that the procedure does not guarantee total protection; circumcised men should also use condoms during sexual intercourse. Condoms, the only measure with a proven effectiveness in HIV prevention, are often left out in mass media reports on the positive effects of AMC. In Poland and elsewhere, the press have often emphasized that "All that men need is one simple operation and they are safe for the rest of their lives." ${ }^{2}$ This might give a false sense of security to circumcised men, reinforcing their reluctance to use condoms ("If AMC protects me against HIV, why use a condom?") and thus increasing the infection risk not only for males but for their female sexual partners as well. In Poland, after years during which HIV infection was predominant among injection drug users, there has been an increase in HIV infections diagnosed among individuals engaging in sexual intercourse. Data from 2009 presented on the National Health Fund website (www.pzh.gov.pl) show that HIV infection was diagnosed in 48 homosexual and bisexual men and 61 persons having heterosexual intercourse, but for $76.5 \%$ of newly reported infections the possible portal of infection was not given.

The said study stressed that circumcision protects men against infection in heterosexual contacts only. Research results on the protective effect of AMC for homosexual and bisexual men are ambiguous. Without a clear explanation, failure to emphasize this difference, again, puts men and their female partners at considerable risk.

The World Health Organization recommendation from 2007 on the popularization of AMC stressed that it is an additional preventive measure-one that cannot replace other methods. It is stated that it is not advisable to promote AMC among men with HIV, but that the procedure should be provided regardless of HIV status. ${ }^{3}$ Many experts are of the opinion that denying the HIV-positive men from receiving circumcision could cause them to be stigmatized; they would look for other places where they can get the procedure done (where the instruments used for the circumcision of children could transfer infections); circumcision could be a marker of HIV-free status and circumcised men could use circumcision as an advantage in negotiations for unprotected sex. ${ }^{4}$

It is still not clear how AMC of an HIV-positive male affects the transfer of infection to his female partner. In 1994, studies conducted in Rwanda (Africa) showed that circumcision of a male partner constitutes a risk factor of HIV infection for women. ${ }^{5}$ The results published in 2007 of studies done in Zimbabwe and Uganda did not show that male circumcision protected women from acquiring HIV. ${ }^{6}$ In Rakai (Uganda), upon the completion of studies showing protective aspects of circumcision on men, other studies continued on the effect of AMC on the infection of female partners by HIV-positive circumcised men. Results analysis showed that the HIV acquisition rate in partners of circumcised men who resume sexual activity before wound healing was $27.8 \%$ compared with $9.5 \%$ in partners of men who underwent circumcision but delayed sex until healing and $7.9 \%$ in partners of uncircumcised men. ${ }^{7}$

The other argument is that AMC reduces the prevalence of sexually transmitted diseases in HIV-positive men. However, earlier studies showed that soap and water can contribute to a threefold drop in HIV infectivity and reduce the number of mononuclear cells in seminal fluid to $87 \%{ }^{8}$ Later studies confirmed that poor hygiene of the penis raises the risk of HIV infection and the authors of the studies postulate making good penile hygiene a desirable social norm. ${ }^{9}$ However, hygiene requires some effort while AMC does not.

By using dynamical simulation models, it was shown that AMC may be helpful in preventing 2 million new HIV infections and 300,000 deaths in the next 10 years in subSaharan Africa and even more in the following decade, but as the authors estimated "In South Africa, if no men were circumcised, we predict that $52 \%$ of HIV-positive adults would be women, whereas if all men where circumcised this proportion would increase to $58 \% .^{\prime 10}$ Definitive results could be obtained from randomized controlled studies on approximately 10,000 couples, which are simply not feasible to conduct.

Additionally, it is still not clear why removing the foreskin reduces HIV infection in men. In March 2010, a study was

Department of Family Medicine and Community Nursing, Medical University of Białystok, Poland. 
published by Dinh et al. ${ }^{11}$ who found no differences in the keratin formation of the inner and the outer aspects of the adult male foreskin, so-as had already been suspectedkeratin layers are unlikely to explain why uncircumcised men are at higher risk of HIV infection. One of the main reasons for the protective effect of AMC can be removal of the preputial sac normally formed by the foreskin, which can serve as an incubator of target cell-virus contact. Therefore, the search must continue to find out why AMC protects against HIV, but only partially and only men. In addition, more should be done to successfully promote proper use of condoms, which is in the best interest of both men and women. As Berer puts it, "Women-partners of circumcised men have an equal right to protection now," ${ }^{12}$ and not in 10-20 years when enough men will have undergone circumcision and the risk of meeting an HIV-positive man will be lower. In countries where the incidence of HIV is highest, women do not have the chance to negotiate the use of condoms with their male partners.

In sub-Saharan Africa the acceptability of AMC for HIV prevention is great, ${ }^{13}$ but the attitudes when it comes to other vulnerable populations, are also changing outside Africa. ${ }^{14}$ In Central Europe, especially in Poland, negative sentiments regarding circumcision date back to the World Ware II period when male circumcision, even in babies, meant a death sentence. Many Americans of Polish origin share similar opinions on circumcision.

AMC therefore should not be promoted for itself, but as package of interventions that include, besides AMC, condoms and female empowerment.

\section{References}

1. Castro JG, Jones DL, Lopez M, Barradas I, Weiss SM. Making the case for circumcision as a public health strategy: Opening the dialogue. AIDS Patient Care STDs 2010;24:367-372.

2. Zagórski S. Wciąż musimy żyć z HIV. Gazeta Wyborcza. December 5, 2008.

3. Male circumcision for HIV prevention: Research implications for policy and programming WHO/UNAIDS technical consultation 6-8 March 2007. Conclusions and recommendations (excerpts). Reprod Health Matters 2001;15:11-14.

4. Wawer MJ, Makumbi F, Kigozi G, et al. Circumcision in HIV-infected men and its effect on HIV transmission to fe- male partners in Rakai, Uganda: A randomized controlled trial. Lancet 2009;374:229-237.

5. Chao A, Butlerys M, Musanganire F, et al. Risk factors associated with prevalent HIV-1 infection among pregnant women in Rwanda. Int J Epidemiol 1994;23:371-380.

6. Turner AN, Morrison CS, Padian NS, et al. Men's circumcision status and women's risk of HIV acquisition in Zimbabwe and Uganda. AIDS 2007;21:1779-1789.

7. Beaten JM, Celum C, Coates TJ. Male circumcision and HIV risks and benefits for women. Lancet 2009;374:182-184.

8. Li JZ, Mack EC, Levy JA. Virucidal efficacy of soap and water against human immunodeficiency virus in genital secretions. Antimicrob Agents Chemother 2003;47:3321-3322.

9. O'Farrell N, Morison L, Moodley P, et al. Association between HIV and subpreputial penile wetness in uncircumcised men in South Africa. J Acquir Immune Defic Syndr 2006;43:69-77.

10. Williams BG, Lloyd-Smith JO, Gouws E, et al. The potential impact of male circumcision on HIV in sub-Saharan Africa. PLoS Med 2006;3:e262.

11. Dinh MH, McRaven MD, Kelley Z, Penugonda S, Hope TJ. Keratinization of the adult male foreskin and implications for male circumcision. AIDS 2010;24:899-906.

12. Berer M. Male circumcision for HIV prevention: what about protecting men's partners? Reprod Health Matter 2008; 16:171-175.

13. Westercamp N, Bailey RC. Acceptability of male circumcision for prevention of HIV/AIDS in sub-Saharan Africa: A review. AIDS Behav 2007;11:341-355.

14. Ruan Y, Qian H-Z, Li D, et al. Willigness to be circumcised for preventing HIV among Chinese men who have sex with men. AIDS Patient Care STDs 2009;23:315-321.

Address correspondence to: Dorota Rogowska-Szadkowska, M.D., Ph.D. Department of Family Medicine and Community Nursing Medical University of Bialystok Department of General Practice and Community Nursing Mieszka I 4B Bialystok Poland 15-054

E-mail: dszadkowska@umwb.edu.pl 